\title{
CLINICAL PROFILE ASSOCIATED WITH HIV RISK IN SPANISH YOUTH
}

\author{
Estefanía Ruiz-Palomino \\ eruiz@uji.es \\ Department of Clinical and Basic Psychology and Psychobiology, Universitat Jaume I \\ Rafael Ballester-Arnal \\ Department of Clinical and Basic Psychology and Psychobiology, Universitat Jaume I \\ Cristina Giménez-García \\ Department of Clinical and Basic Psychology and Psychobiology, Universitat Jaume I \\ Beatriz Gil-Juliá \\ Department of Clinical and Basic Psychology and Psychobiology, Universitat Jaume I \\ María Dolores Gil-Lario \\ Department of Developmental and Educational Psychology, Universitat de València
}

Fecha de Recepción: 1 Marzo 2018

Fecha de Admisión: 10 Abril 2018

\begin{abstract}
Heterosexual transmission is the second route of new HIV infection diagnoses in Spain. A high percentage of young people use condom inconsistently. Beyond cognitive factors, emotional variables seem to be associated with sexual risk behavior. The aim was to examine the differential clinical profile between young people at risk and no-risk for HIV infection. A total of 424 heterosexuals were evaluated ( $M$ age $=20.62 ; S D=2.16)$, and distributed into two groups: risk group $(60.7 \%)$ and non-risk group (39.3\%). They completed the AIDS Prevention Questionnaire, the Beck Depression Inventory, the Rosenberg Self-Esteem Scale, the Penn State Worry Questionnaire, and the Brief Fear of Negative Evaluation Scale. Young people who do not use condoms consistently scored higher on worry about health, fear of negative evaluation, depressive symptoms and self-esteem. But no statistical differences were obtained between the group of risk and non-risk group. A multiple regression logistic analysis indicated that depression $(B=.054, p=.015)$ and age $(B=.135, p=.010)$ explained $5.6 \%$ of the variance in condom use. It would be relevant to continue studying the role of negative affective states and emotional self-regulation in risky sexual behaviors among this population.
\end{abstract}

Keywords: HIV prevention; condom use; depressive symptoms; emotional self-regulation; youth

\section{INTRODUCTION}

Young people under the age of 29 represent a $25.8 \%$ of HIV new infections in Spain. In this 
group, the second route of transmission is the heterosexual intercourse (26.5\%: $16 \%$ in men and $81.6 \%$ in women) (Plan Nacional sobre el Sida, 2017). Many studies based on the Spanish context have shown that between 25 per cent and 50 per cent of young people have not used condoms consistently (Ballester, Gil, Giménez, \& Ruiz, 2009; Folch, Álvarez, Casabona, Brotons, Castellsagué, \& Grupo Jóvenes e Internet, 2015; Lameiras, Faílde, Bimbela, \& Alfaro, 2008; Prat, Planes, Gras, \& Sullman, 2016; Yubero, Larrañaga, \& Yubero, 2013). Cognitive variables such as knowledge about HIV transmission routes, attitudes towards condom use or beliefs about HIV-AIDS have been widely studied (Ballester et al., 2009; Ballester-Arnal, Gil-Llario, Ruiz-Palomino, \& Giménez-García, 2013; Espada, Morales, \& Orgilés, 2014; Lameiras et al., 2008; Prat et al., 2013; Yubero et al., 2013). However, limited research exists about the relationship between affective factors and condom use behavior (Ballester-Arnal, Ruiz-Palomino, \& Gil-Llario, 2017; Norton, Bogart, Cecil, \& Pinkerton, 2005).

The scientific literature has shown different ways of influence between self-esteem and risk of HIV infection. Self-esteem was defined by Rosenberg (1989) as a favorable or unfavorable attitude toward oneself. Low self-esteem is associated with early sexual debut or deficits in sexual assertiveness (Enejoh, Pharr, Mavegam, Olutola, Karick, \& Ezeanolue, 2016; Ramiro, Teva, Bermúdez, \& Buela-Casal, 2013, Sylvester, 2014). Contrarily, high self-esteem increases positive attitudes towards condom or improves perception of condom use negotiation (Villegas, Cianelli, GonzalezGuarda, Kaelber, Ferrer, \& Peragallo, 2013; Yang, Dedovic \& Zhang, 2010), as well as goes up the engagement in unsafe sexual practices (Ruiz-Palomino, Ballester-Arnal, Gil-Llario, \& GiménezGarcía, 2017, Ugoji, 2014).

In addition, studies about negative affect and condom use behavior have indicated that factors such as depression (Anatale \& Kelly, 2015; Islam \& Laugen, 2015; Asarnow, Zeledon, D’Amico, Laborde, Anderson, Avina et al., 2014), anxiety as a pathological pole of the worry (Elkington, Bauermeister, \& Zimmerman, 2010; Sales, Spitalnick, Milhausen, Wingood, DiClemente, Salazar et al, 2009) or social anxiety (Agardh, Cantor-Graae, \& Ostergren, 2012; Bell, 2009; Hart \& Heimberg, 2005; MacDonald, McKenna, \& Mouck, 2015) are associated with unprotected intercourse. Two explanatory mechanisms are related, one focused on the probability approach and the other focused on the self-regulation approach. Firstly, positive affect towards oneself would facilitate feeling security for coping unsafe sexual situations, but at the same time, it would underestimate risks of certain hazard situations. Secondly, negative affect would increase vulnerability and consequently would reduce sexual risk engagement, or it would facilitate negative feelings that prevent safe sexual intercourses (MacDonald \& Matineau, 2002; Quinn \& Fromme, 2010; Sarno, Mohr, \& Rosenberger, 2017).

Understanding this complex background about the relation between above mentioned clinical variables and use of condom is a challenge for HIV prevention. We hypothesize that sexual risk behavior is related to higher worry about health, fear of negative evaluation, depression and lower self-esteem. Therefore the main aim of this study is to examine the existence of a clinical risk profile among heterosexual youth at risk of HIV infection.

\section{METHOD}

\section{Participants}

A random sample of 424 Spanish young heterosexual people were evaluated $(60.4 \%$ were women and $39.6 \%$ were men). All participants had university studies and a mean age of 20.62 years old $(S D=2.62)$. Given that the only safe behavior to prevent HIV infection entails the systematic use of the condom, it was decided to change the criterion variable in dichotomous variable. 
The no-risk group (NRG), made up of participants who reported that 'always' used condoms: $39.3 \%, 60.8 \%$ were women and $39.2 \%$ were men $\left(M_{a g e}=20.38 ; S D=2.09\right)$.

The risk group (RG), made up of participants who reported that not systematically used condoms: $60.7 \%, 59.3 \%$ were women and $40.7 \%$ were men $\left(M_{a g e}=20.91 ; S D=2.19\right)$.

\section{Procedure}

The sample collection process was carried out, approximately, in two years. The Research Unit organized preventive activities for on World AIDS Day on campuses addressed to university community per each year. Interested people were informed about the participation in the research project. Nearly six hundred college students asked about it and 487 agreed with participating. This sample represents around 5 percent of the Universitat Jaume I population at these ages. The first contact was made by email or phone. In this step, they were informed about aims and procedure. Paper self-completion questionnaires and informed consent form were filled out in, approximately, 90 minutes. Incomplete questionnaires were eliminated $(n=63)$. In the present study, we applied the guidelines of the Spanish data protection law known as Ley Orgánica de Protección de Datos (LOPD) and the Declaration of Helsinki, to guarantee the confidential nature and treatment of the data obtained and to protect the ethical principles for research involving human beings.

\section{Measurement}

AIDS Prevention Questionnaire (CPS). This instrument was made up of 65 items that attempt to gather up the components considered to be relevant in various HIV prevention models. The selected item is concerned about the use of condom behavior (How often have you used a condom in vaginal sex?). The Likert-type scale response could be never, sometimes, often or always (Ballester, Gil, \& Giménez, 2007; Ballester-Arnal, Gil-Llario, Ruiz-Palomino, \& Morell-Mengual, in press).

Rosenberg Self-Esteem Scale (RSE). An instrument that measures overall feelings of self-worth or self-acceptance. A 10-item scale whose statements are answered using 4-point Likert scale ranging from one (strongly agree) to four (strongly disagree). The Spanish version by Martín-Albo, Núñez, Navarro, and Grijalvo (2007) was used (internal consistency of .85 and .88).

Beck Depression Inventory II (BDI-II). An instrument that assess the existence and severity of depression symptoms as listed in the DSM. There is a four-point scale for each item ranging from zero to three, sorted from lowest to highest severity. The Spanish version by Sanz, Navarro, and Vázquez (2003) was used (internal consistency of .89).

Penn State Worry Questionnaire (PSWQ). An instrument that evaluates a general tendency to experiment worry. It is a 5-point scale ranging from one (not at all typical of me) to five (very typical of me). This is an experimental and adapted version from the worry health version by Castañeiras (2001) was used (internal consistency of .90).

The Brief Fear of Negative Evaluation Scale (BFNE). An instrument that measures the degree of apprehension at the perception of being negatively evaluated. It contains 12 -items on a 5-point Likert scale ranging from one (not at all characteristic of me) to five (extremely characteristic of me). The Spanish version by (Gallego, Botella, Quero, Baños, and García-Palacios (2007) was used (internal consistency of .90).

\section{Analyses}

To select the criterion variable and to carry out the statistical analyses, biological risks of the practices evaluated were taken into account (oral sex, vaginal sex and anal sex), as well as their frequency. It was chosen as a dependent variable (DV) condom use in vaginal sex, due to it represents one of the highest risk sexual behaviors for HIV infection. The item that evaluated self-reported 
behavior concerning condom use in sexual relations was subsequently recodified as a dichotomous variable: no-risk meant systematically use of condom ("always") and risk meant not systematically use of condom ("never", "sometimes", and "often") Initially, differences in the clinical variables as a function of group were evaluated. This comparison between independent samples (risk vs no-risk) was carried out using the t-test on quantitative variables and Cohen's d-test.

Following the differential study, a multivariate analysis was carried out using a multiple logistic regression analysis; this enabled us to predict or estimate the probability that a subject might find himself or herself in the situation of interest (belonging to a $R G$ ) as a function of certain individual characteristics. Logistic regression was the chosen analytical method for two reasons: (1) the conditions of multivariate normality, homoscedasticity, and linearity are not required, and (2) the model may incorporate independent variables of different types (Hair, Anderson, Tatham \& Black, 1995).

\section{RESULTS}

Young people had medium-high scores on self-esteem $(x=30.81, S D=4.23)$. Moreover, the average score on depression indicates the absence of clinical problem $(x=6.62 ; S D=6.15)$. With regard to the fear of negative evaluation, the average score $(x=35.98, S D=8.52)$ is higher than the nonclinical cut-off points ( 26.50 for men and 27.61 for women) and lower than clinical cut-off points (41.95 for men and 43.45 for women). Finally, the average score of worry about health ( $x=40.90$, $S D=9.69$ ) is generally within the range of non-clinical population (25th percentile).

Regarding the differential analysis, young people who do not use condoms consistently scored higher on worry about health, fear of negative evaluation, depressive symptoms and self-esteem. But no statistical differences and low effect size were obtained between the group of risk and nonrisk group (see Table 1).

Table 1.

Group differences in clinical variables (t-tests and Cohen's d).

\begin{tabular}{|c|c|c|c|c|c|c|c|}
\hline & \multicolumn{2}{|c|}{ Non-risk Group } & \multicolumn{2}{|c|}{ Risk Group } & \multirow[b]{2}{*}{$t$} & \multirow[b]{2}{*}{$p$} & \multirow{2}{*}{$\begin{array}{c}d \\
\text { (IC lower; } \text { higher })\end{array}$} \\
\hline & $M$ & $S D$ & $M$ & $S D$ & & & \\
\hline Self-esteem & 30,81 & 4,12 & 30,96 & 4,31 & $-0,340$ & 0.734 & $\begin{array}{c}-0,0353 \\
(-0,238 ; 0,168)\end{array}$ \\
\hline $\begin{array}{l}\text { Worry about } \\
\text { health }\end{array}$ & 40,39 & 10,32 & 41,59 & 9,04 & 1,173 & 0.241 & $\begin{array}{c}-0,1252 \\
(-0,328 ; 0,078)\end{array}$ \\
\hline $\begin{array}{l}\text { Fear of } \\
\text { negative } \\
\text { evaluation }\end{array}$ & 35,97 & 8,14 & 36,13 & 8,77 & $-0,190$ & 0.849 & $\begin{array}{c}-0,0187 \\
(-0,222 ; 0,184)\end{array}$ \\
\hline Depression & 5,93 & 5,94 & 6,99 & 6,34 & $-1,641$ & 0.102 & $\begin{array}{c}-0,1710 \\
(-0,374 ; 0,032) \\
\end{array}$ \\
\hline
\end{tabular}

Following on from this, a multiple regression logistic analysis was performed with the enter method. The value of $R$ square Naglekerke indicates that the proposed model accounts for $5,6 \%$ of the variance of the dependent variable. This equation generated two explanatory variable, depression $(B=.054, p=.015)$ and age $(B=.135, p=.010)$. Gender does not reveal an influence on condom use $(B=-.059, p=.796)$. The odds ratio value indicates that an increase in depression means increased risk in $1.055(95 \% \mathrm{Cl}: 1.010,1.102)$ and an increase in age means increased risk in $1.145(95 \% \mathrm{Cl}$ : $1.032,1.270)$. The Hosmer-Lemeshow test obtained no statistical significance $(\chi 2=7.270 ; p=$ .508 ), indicating goodness-of-fit model. A good classification result is obtained with an average of $62 \%$ of classifications being correct. 


\section{DISCUSSION}

Inconsistent condom use increases the risk of HIV infection, sexually transmitted diseases and unwanted pregnancies. Consequently, 60 per cent of the evaluated young people are at risk of infection. These percentages are similar to the latest data reported on inconsistent condom use by other authors in this country. For example: 57.9 per cent in Gerona (Prat et al., 2016), between 58.4 and 75.6 per cent in all Catalonia (Folch et al., 2015) or between 47.6 and 52.8 per cent of school students from the east, center and north of Spain (Espada et al., 2014).

Depression and age are the only explanatory variables of condom use among young Spaniards in the regression analysis. Studies carried out with young people from other countries have demonstrated the influence of negative affect in unprotected sex (Anatale \& Kelly, 2015; Islam \& Laugen, 2015; Jardin, Sharp, Garey, \& Zvolensky, 2016). Although the explanatory mechanism of this relationship needs further investigation, several hypotheses have been proposed. Psychological theories of depression that focus on problems with cognitive functioning. The cognitive style of people with depressive symptoms is related to the motivational and affective responses. It is considered that the negative affective states skew attention and interpretation of situations, for example, negative effect on self-determination and condom use negotiation skills; and affect the processes of selfregulation of emotions experienced, for example, increasing the consumption of alcohol and drugs during sex (Jackson, Seth, DiClemente, \& Lin, 2015; Lee, Salman, \& Fitzpatrick, 2009; MacDonald \& Matineau, 2002; Quinn \& Fromme, 2010). In addition, a lesser use of condoms along ages could be explicated by the preference to employ long-term mating strategies (Mathes, King, Miller \& Reed, 2002).

Although some studies have shown that low self-esteem, high fear of negative evaluation and high worry about health could be influenced to risky sexual behavior, significant influences were not found in our study. Youth who do not use condoms consistently are only very slightly more concerned about their health, are a little more apprehensive of the evaluation of others and have a somewhat higher self-esteem. In this study evaluated clinical variables have shown as little relevant in explaining the behavior of condom use. It is possible that these dimensions can act on behavior through other mediating variables (e.g. condom use self-efficacy, self-perception of HIV risk, etc.) or that these more general dimensions are not relevant to explain concrete behavior such as condom use, having more weight, other specific or situational factors (Ballester-Arnal, Ruiz-Palomino \& Gil-Llario, 2016; Carvalho, Alvarez, Barz \& Schwarzer, 2015; Harvey, Beckman, Gerend, Bird, Posner, Huszti et al., 2006).

The conclusions of this study are subject to certain limitations that should be addressed in future studies. First, it has been chosen as criterion variable condom use in vaginal sex. The high risk of the practice and the high prevalence of behavior in youth have prevailed when the decision was taken. However, it is important to analyze whether the same results are replicated in other sexual practices and risk situations, for example in oral sex, anal sex or having sex after drugs consumption. Secondly, it was decided to create a dichotomous variable (group type) depending on the consistent condom use, appealing to a biological criterion of risk of infection (only consistent condom use ensures no HIV transmission). This methodological decision may have influenced in the results. If it is considered the behavior as a continuous variable in which there are different degrees of condom use, perhaps the profile of young people who never used condoms and those who use it inconsistently may be different. Further research around major individual factors related to sexual risk behaviors for HIV infection is necessary, in order to preventive interventions enhance those personal resources to minimize risk factors. 


\section{ACKNOWLEDGMENTS}

This study was supported by Universidad Jaume I-Fundación Bancaixa (P1 1B2006-19); and the Spanish Foundation for AIDS Research and Prevention known as Fundación para la Investigación y la Prevención del Sida en España (exp. 36639/07).

\section{REFERENCES}

Agardh, A., Cantor-Graae, E., \& Ostergren, P.O. (2012). Youth, sexual risk-taking behavior, and mental health: a study of university students in Uganda. International Journal of Behavioral Medicine, 19(2), 208-216.

Anatale, K. \& Kelly, S. (2015). Factors influencing adolescent girls' sexual behavior: a secondary analysis of the 2011 youth risk behavior survey. Issues in Mental Health Nursing, 36(3), 217221.

Asarnow, J.R., Zeledon, L.R., D’Amico, E., LaBorde, A., Anderson, M., Avina, C. et al. (2014). Depression and Health Risk Behaviors: towards optimizing primary care service strategies for addressing risk. Primary Health Care, 4(1), 152.

Ballester, R., Gil, M.D., \& Giménez, C. (2007, june). El Cuestionario de Prevención del Sida (CPS): Análisis de la fiabilidad y validez. In: Seisida, editors. Sida, un nuevo escenario. Proceedings of the X Congreso Nacional sobre el Sida de la Sociedad Española Interdisciplinaria de Sida; San Sebastián, Spain: Seisida; p. 135.

Ballester, R., Gil, M.D., Giménez, C., \& Ruiz, E. (2009). Actitudes y conductas sexuales de riesgo para la infección por VIH/Sida en jóvenes españoles. Revista de Psicopatología y Psicología Clínica, 14(3), 181-191.

Ballester-Arnal, R., Gil-Llario, M.D., Ruiz-Palomino, E., \& Giménez-García, C. (2013). Autoeficacia en la prevención sexual del Sida: la influencia del género. Anales de Psicología, 29(1), 76-82.

Ballester-Arnal, R., Ruiz-Palomino, E., \& Gil-Llario, MD. (2017). Structural equation modeling test of an integrated model of Spanish youth's condom use. AIDS \& Behavior, 21(5), 1407-1416.

Bell, J. (2009). Why embarrassment inhibits the acquisition and use of condoms: A qualitative approach to understanding risky sexual behaviour. Journal of Adolescence, 32(2), 379-391.

Carvalho, T., Alvarez, M.J., Barz, M., \& Schwarzer, R. (2015). Preparatory behavior for condom use among heterosexual young men: a longitudinal mediation model. Health Education \& Behavior, 42(1), 92-99.

Castañeiras Gebrikian C.E. (2001). Avances en Psicopatologia y Clinica de la hipocondría [Dissertation]. Valencia: Universidad de Valencia.

Elkington, K.S., Bauermeister, J.A., \& Zimmerman, M.A. (2010). Psychological distress, substance use, and HIV/STI risk behaviors among youth. Journal of Youth and Adolescence, 39(5), 514527.

Enejoh, V., Pharr, J., Mavegam, B. O., Olutola, A., Karick, H., \& Ezeanolue, E. E. (2016). Impact of self-esteem on risky sexual behaviors among Nigerian adolescents. Aids Care, 28(5), 672-676.

Espada, J.P., Morales, A., \& Orgilés, M. (2014). Riesgo sexual en adolescentes según la edad de debut sexual. Acta Colombiana de Psicología, 17(1), 53-60.

Folch, C., Álvarez, J.L., Casabona, J., Brotons, M., Castellsagué, X., \& Grupo Jóvenes e Internet. (2015). Factors associated with sexual risk behaviour among young people in Catalonia. Revista Española de Salud Pública, 89(5), 471-85.

Gallego, M.J., Botella, C., Quero, S., Baños, R.M., \& García-Palacios, A. (2007). Propiedades psicométricas de la Escala de Miedo a la Evaluación Negativa versión breve (BFNE) en muestra clínica. Revista de Psicopatología y Psicología Clínica, 12(3), 163-176. 
Hair, J.F., Anderson, R.E., Tatham, R.L., \& Black, W.C. (1995). Multivariate data analysis. Englewood Cliffs: Prentice Hall.

Hart, T. \& Heimberg, R.G. (2005). Social anxiety as a risk factor for unprotected intercourse among gay and bisexual male youth. AIDS \& Behavior, 9(4), 505-512.

Harvey, S.M., Beckman, L.J., Gerend, M.A., Bird, S.T., Posner, S., Huszti, H.C., \& Galavotti, C. (2006). A conceptual model of women's condom use intentions: integrating. AIDS Care, 18(7), 698-709.

Islam, N. \& Laugen, C. (2015). Gender differences in depression and condom use among sexually active Canadians. Journal of Affective Disorders, 174, 511-515.

Jackson, J.M., Seth, P., DiClemente, R.J., \& Lin, A. (2015). Association of Depressive Symptoms and Substance Use With Risky Sexual Behavior and Sexually Transmitted Infections Among African American Female Adolescents Seeking Sexual Health Care. American Journal of Public Health, 105(10), 2137-2142.

Jardin, Ch., Sharp, C., Garey, L., \& Zvolensky, M.J. (2016). The role of impulsivity in the relation between negative affect and risky sexual behaviors. Journal of Sex \& Marital Therapy. DOI: 10.1080/0092623X.2016.1141821.

Lameiras, M., Faílde, J.M., Bimbela, J.L., \& Alfaro, N. (2008). Male condom usage in vaginal intercourse relations by Spanish youngsters aged fourteenth to twenty fourth. Diversitas, 4(2), 401415.

Lee, Y.H., Salman, A., \& Fitzpatrick, J.J. (2009). HIV/AIDS preventive self-efficacy, depressive symptoms, and risky sexual behavior in adolescents: a cross-sectional questionnaire survey. International Journal of Nursing Studies, 46(5), 653-660.

MacDonald, T.K. \& Martineau, A.M. (2002). Self-esteem, mood, and intentions to use condoms: When does low self-esteem lead to risky health behaviors? Journal of Experimental Social Psychology, 38, 299-306.

MacDonald, T.K., McKenna, C., \& Mouck, L.C. (2015). The Person and the Partner: Individual Differences Moderate the Relationship Between Partner Feedback and Condom Use. AIDS \& Behavior. doi: 10.1007/s10461-015-1153-4.

Mathes, E.W., King, C.A., Miller, J.K., \& Red, R.M. (2002). An evolutionary perspective on the interaction of age and sex differences in short-term sexual strategies. Psychological Reports, 90(3), $949-956$.

Martín-Albo, J., Núñez, J.L., Navarro, J.G., \& Grijalvo, F. (2007). The Rosenberg Self-Esteem Scale: Translation and validation in university students. The Spanish Journal of Psychology, 10(2), 458-467.

Norton, T.R., Bogart, L.M., Cecil, H., \& Pinkerton, S.D. (2005). Primacy of affect over cognition in determining adult men's condom-use behavior: a review. Journal of Applied Social Psychology, 35(12), 2493-2534.

Plan Nacional sobre el Sida - S.G. de Promoción de la Salud y Epidemiología / Centro Nacional de Epidemiología - ISCIII. Área de Vigilancia de VIH y Comportamientos de Riesgo. Vigilancia Epidemiológica del VIH y sida en España 2016: Sistema de Información sobre Nuevos Diagnósticos de VIH y Registro Nacional de Casos de Sida. Madrid; Noviembre de 2017.

Prat, F., Planes, M., Gras, M.E., \& Sullman, M.J.M. (2016). Perceived pros and cons of condom use as predictors of its consistent use with a heterosexual romantic partner among young adults. Current Psychology, 35(1), 13-21.

Quinn, P.D. \& Fromme, K. (2010). Self-Regulation as a Protective Factor against Risky Drinking and Sexual Behavior. Psychology of Addictive Behaviors, 24(3), 376-385. 
Ramiro, M. T., Teva, I., Bermúdez, M. P., \& Buela-Casal, G. (2013). Social support, self-esteem and depression: Relationship with risk for sexually transmitted infections/HIV transmission. International Journal of Clinical and Health Psychology, 13, 181-188.

Rosenberg, M. (1989). Society and the adolescent self-image. Middletown, CT: Wesleyan University Press.

Ruiz-Palomino, E., Ballester-Arnal, R., Gil-Llario, M.D., \& Giménez-García, C. (2017). El papel de la autoestima en la prevención del VIH de los jóvenes. International Journal of Developmental and Educational Psychology, 1(1), 15-22.

Sales, J.M., Spitalnick, J., Milhausen, R.R., Wingood, G.M., DiClemente, R.J., Salazar, L.F. et al. (2009). Validation of the worry about sexual outcomes scale for use in STI/HIV prevention interventions for adolescent females. Health Education Research, 24(1), 140-152.

Sanz, J., Navarro, M.E., \& Vázquez, C. (2003). Adaptación española del Inventario para la Depresión de Beck II (BDI-II): Propiedades psicométricas en estudiantes universitarios. Análisis y Modificación de Conducta, 29(124), 239-288.

Sarno, E.L., Mohr, J.J., \& Rosenberger, J.G. (2017). Affect and condom use among men who have sex with men: A daily diary study. AIDS \& Behavior, 21, 1429-1443.

Sylvester, 0. A. (2014). Influence of self-esteem, parenting style and parental monitoring on sexual risk behaviour of adolescents in Ibadan. Gender \& Behaviour, 12(2), 6341-6353.

Ugoji, F. N. (2014). Determinants of risky sexual behaviours among secondary school students in Delta State Nigeria. International Journal of Adolescence and Youth, 19(3), 408-418.

Villegas, N., Cianelli, R., Gonzalez-Guarda, R., Kaelber, L., Ferrer, L., \& Peragallo, N. (2013). Predictors of self-efficacy for HIV prevention among Hispanic women in South Florida. The Journal of the Association of Nurses in AIDS Care: JANAC. 24(1), 27-37.

Yang, J., Dedovic, K., \& Zhang, Q. (2010). Self-esteem and risky decisionmaking: An ERP study. NEUROCASE, 16, 512-519.

Yubero, M., Larrañaga, E., \& Yubero, S. (2013). Attitudes and risk sexual behavior of pregnancy in university students. Journal of Child and Adolescent Psychology, 4(2), 11-29. 